INTERNATIONAL JOURNAL OF RESEARCHES IN BIOSCIENCES, AGRICULTURE AND TECHNOLOGY

(C) VISHWASHANTI MULTIPURPOSE SOCIETY (Global Peace Multipurpose Society) R. No. MH-659/13(N) www.vmsindia.org

\title{
STUDIES ON FACTORS OF AIR POLLUTION IN AKOLA DISTRICT
}

\author{
S.P. Wagh \\ Department of Chemistry, Shri Shivaji Arts, Commerce \& Science College, \\ Akot, Dist- Akola (M.S.)
}

Abstract:

Present paper reveals the current scenario of Air Pollution of Akola district. The population explosion is the main problem or reason for the air pollution. When the population of Akola district was small and man was with limited agricultural practices, there was ecological balance. But by the increase in population, more people combined with modern technology and frontier concept has produced our ecological crisis. Many factors along with human population explosion, unplanned urbanization and deforestation, profit oriented capitalism and technological advancement are responsible for air pollution in the district.

Keywords: Pollution, Akola, Air quality, Suspended matter. CPCB

\section{Introduction:}

Clean air is the foremost requirement to sustain healthy lives of humankind and those of the supporting ecosystems which in return affect the human wellbeing. Release of various gaseous emissions and particulate matter (PM) has been on the rise due to rampant industrialized growth Anthropogenic emissions of various kinds are being pumped into the atmosphere (called primary pollutants) and lead to the formation of new pollutants due to chemical reactions in the atmosphere (called secondary pollutants). These are building up the concern of ambient air pollution (AAP) as a prominent global threat to human health in many ways. For instance, according to the Fifth Assessment Report of the IPCC 'nearly all the non-CO2 climate-altering pollutants are health damaging, either directly or by contributing to secondary pollutants in the atmosphere'.

It is essential that the hazardous impacts from environmental pollution are regularly reported and monitored. Of the various kinds of pollution, the air pollution has attracted high priority in respect of environmental regulation since the environmental damage due to such pollution mostly affects human well-being directly by way of adverse health effects on the population exposed to it. Air quality has deteriorated in most large cities in India, a situation driven by population growth, industrialization and increased vehicle use. Integrated air quality management (AQM), which is an evaluation and monitoring tool, is a challenge to carry out in most developing countries because of the lack of information on sources of air pollution and insufficient ambient air monitoring data that is available in the public domain Urban air pollution is largely a result of combustion of fossil fuels that are used in transportation, power generation, industrial sector, and other economic activities. Household air pollution (HAP), also known as indoor air pollution (IAP), is a serious area of concern in rural spaces, as majority of this population continues to depend on traditional biomass for cooking and space heating and depend on kerosene or other liquid fuels for lighting, all of which are highly likely to lead to high levels of HAP. More than $70 \%$ of the population in India depends on traditional fuels (firewood, crop residue, cow dung, coal and lignite) for cooking and almost $32 \%$ depend on kerosene for lighting purposes. About 3 billion people in the world (more than $40 \%$ of the global population) rely on traditional biomass for the purpose of cooking and an estimated 500 million households rely on kerosene and similar for the purpose of lighting (WHO, 2015). In rural India, for instance, only $11.4 \%$ of the households use LPG for cooking.

There are many studies across the world and also in India to prove that outdoor and indoor air pollution is a serious environmental risk factor that causes or aggravates acute and chronic diseases. Pairing city-level air pollution measures with child level data from the National Family Health Survey (2005-06) for six cities in India shows that an increase in ambient air pollution significantly increases child morbidity (Ghosh and Mukherjee 2010). The six cities considered in the city were Chennai, Delhi, Hyderabad, Indore, Kolkata and Nagpur. The study found that a rise in ambient air pollution significantly increases the likelihood of a child suffering from cough and fever in the past week. However, the type of cooking fuel used at home is not significantly related to child morbidity after accounting for ambient air pollution and other child- and household-level control variables. Thus, while bad air is bad for child health, ambient air pollution is a more significant determinant of 
the child health outcomes. A significant correlation between the

two child morbidity outcomes - fever and cough. Controlling citywide air pollution could significantly lower child morbidity, and should receive greater emphasis in urban planning and infrastructure development.

\section{Material and Methods: \\ Air Quality Measurement \\ A. High Volume Sampler}

It is used to monitor an ambient air quality for suspended particulate matter (SPM). It also has a provision to collect samples of gaseous pollutants such as $\mathrm{SO} 2, \mathrm{NO} 2, \mathrm{CO}$ etc. from ambient air by absorbing them in appropriate reagents kept in impinger tube followed by a further analysis in the laboratory. It can be used to collect air quality samples in industrial areas, urban areas and other sensitive areas. Air is drawn into a covered housing and through a filter by a high flow rate blower at 1.1 to $1.5 \mathrm{~m}^{3} / \mathrm{min}$ that allows suspended particulate matter to collect on the filter surface. Particles with diameter of 0.1 to 100 micrometer are collected on glass fiber filters. SPM is calculated by measuring the mass collected on filter and volume of air sample. Sampling at an average flow rate of $1.1 \mathrm{~m}^{3} / \mathrm{min}$ for $24 \mathrm{hrs}$ gives an adequate sample even in an atmosphere having concentration particulates as low as $1 \mathrm{\mu gm} / \mathrm{m}^{3}$, if particulate levels are unusual high the satisfactory sample may be obtained in 6 to $8 \mathrm{hrs}$ or less.

\section{B. Measurement of Suspended Particulate Matter}

The mass concentration of suspended particulates in air is calculated by measuring the mass of collected particles and the volume of air sampled .In HVS, the flow rate of air passing through the filter is monitored by measuring the pressure drops across the orifice plate between the filter holder and the blower. The manometer scale used to measure the pressure drop is calibrated in air flow in cubic meter/minute. A time totaliser records the time in minutes for which instrument has sample the air. The mass of particulates is measured gravimetrically using a balance capable of reliable measurement to the nearest milligram.

Indoor air quality has emerged as one of the most important issues of environment and health worldwide. Household air pollution (HAP) due to biomass cooking fuel use is an important risk factor for a range of diseases, especially among adult women who are primary cooks, in India (Lin SS et al 2010). India has recently identified HAP as one of the key indicators in its
National Monitoring Framework for Prevention and Control of Non-Communicable Diseases (MoHFW 2012). Biomass fuel remains a widely used energy source in rural India where nearly $80 \%$ of households use them as the primary cooking fuel. In contrast, the majority of urban households use liquefied petroleum gas (LPG) as the primary cooking fuel; however, about $19 \%$ of urban households use biomass fuel for cooking purposes. Poverty, inaccessibility to improved cooking fuel, and lack of awareness about harms of biomass emissions are among the major factors that drive their widespread use (MoSPI 2010). Use of biomass fuel leads to harmful health effects due to the emission, during its incomplete combustion, of a large number of air pollutants such as carbon monoxide $(\mathrm{CO})$, sulfur dioxide (SO2), respirable particulate matter (PM2.5 and PM10), polycyclic aromatic hydrocarbon $(\mathrm{PAH})$, benzene, and metals like lead and copper.

\section{Result and Discussion:}

It has been estimated that about thousands of cases of chronic bronchitis, Tuberculosis , cataract among adult women and stillbirths across Akola are attributable to household air pollution due to biomass cooking fuel. Several studies have linked biomass cooking fuel with adverse pregnancy outcomes such as preterm births, low birth weight and post-neonatal infant mortality, but very few have studied the associations with cooking fuel independent of other factors associated with stillbirths. Using India's 2003/04 District Level Household Survey II data, it has been found that usage of biomass and kerosene cooking fuels by women is related to stillbirths. Nearly $12 \%$ of these stillbirths can be prevented by providing access to cleaner cooking fuels. The monitoring has been carried out using High Volume sampler machine, $8 \mathrm{hrs}$ sampling of pollutants was carried out for nearly 09 months. It can be seen that the concentration of SPM ranges from $39.93 \mathrm{\mu g} / \mathrm{m}^{3}$ to $147.56 \mathrm{\mu g} / \mathrm{m}^{3}$. It can also be seen that the concentration of $\mathrm{SO} 2$ ranges from $19.25 \mathrm{\mu g} / \mathrm{m}^{3}$ to $38.16 \mu \mathrm{g} / \mathrm{m}^{3}$ and the concentration of NO2 ranges from $6.68 \mu \mathrm{g} / \mathrm{m}^{3}$ to $9.84 \mathrm{\mu g} / \mathrm{m}^{3}$. It was observed that high $\mathrm{SO} 2$ concentrations were generally associated with the wind blowing from WNW-NW directions, and the high SPM concentrations were usually related to the wind blowing from W-NW directions. The sampling was carried out for nearly nine months and SPM, SO2, NO2 were analyzed for $8 \mathrm{hrs}$. The average concentration for SPM, SO2, and NO2 was found to be 91.61 $\mu \mathrm{g} / \mathrm{m}^{3}, 27.18 \mu \mathrm{g} / \mathrm{m}^{3}, 8.14 \mu \mathrm{g} / \mathrm{m}^{3}$ respectively. 
According to $\mathrm{CPCB}$ recommendation the pollutants concentration should be within 200 $\mu \mathrm{g} / \mathrm{m}^{3}$ for $\mathrm{SPM}, 80 \mu \mathrm{g} / \mathrm{m}^{3}$ for $\mathrm{SO} 2$ and $\mathrm{NO} 2$.

\section{Conclusion:}

Air Quality Monitoring was carried out to know about the concentration three major pollutants namely SPM, SOx, and NOx at the site selected for the study. For overcoming this problem in Akola city Maharashtra,India government should take following action plan because there is chance of IT sector and for agricultural based industries. 1. Check the traffic signals properly.2.Proper management of traffic.3.Divert all the traffic for another subway.4.Akola city declare as "No Horn city." 5.Particulate emission could be effectively controlled if dust control measures are adopted.6 Detailed studies over a longer period are required to assess spatial and temporal variations in concentrations of particulate matter around the city due to the new construction activities.

\section{References:}

Greenstone M.,Nilekani J, Pande R, Ryan N, Sudarshan $A$ and Sugathan $A$ (2015). Lower Pollution, Longer Lives: Life Expectancy Gains if India Reduced Particulate Matter Pollution. Economic and Political Weekly.Vol 1 No 8

Ghosh A. and Mukherjee A (2010). Air Pollution and Child Health in Urban India. Indian Statistical Institute : New Delhi. India

Kumar R., Goel N, Gupta N, Singh N, Nagar S, and Mittal J (2013). Indoor Air Pollution and Respiratory Illness in Children from Rural India: A Pilot Study. Vallabhbhai Patel Chest Institute. University of Delhi: New Delhi, India

Lim SS, Vos T, Flaxman AD, Danaei G, Shibuya K, Adair- Rohani $H$, et al (2010). A comparative risk assessment of burden of disease and injury attributable to 67 risk factors and risk factor clusters in 21 regions, 19902010: a systematic analysis for the Global Burden of Disease Study 2010. Lancet 2012; 380: 222460

Sehgal M, Rizwan S and Krishnan A (2014). Disease burden due to biomass cooking-fuel-related household air pollution among women in India. Global Health Action : Volume 7 Nov. 2014 